Short communication

\title{
LOW PREVALENCE OF WOLBACHIA INFECTION IN UKRAINIAN POPULATIONS OF DROSOPHILA
}

\author{
S.V.Serga ${ }^{1}$, P.A. Kovalenko ${ }^{1}$, N.V. Gora ${ }^{1}$, A.V. Lavrinienko ${ }^{2}$, S.V. Demidov ${ }^{1}$, \\ F. Mestres $^{3}$, M. Pascual ${ }^{3}$, I.A. Kozeretska ${ }^{1}$ \\ ${ }^{1}$ Taras Shevchenko National University of Kyiv, \\ 64 Volodymyrska str, Kyiv, 01601, Ukraine \\ ${ }^{2}$ Department of Ecology and Genetics, University of Oulu, 90014, Finland \\ ${ }^{3}$ Universitat de Barcelona, Facultat de Biologia, Departament de Genètica, \\ Barcelona, E-08028, Spain \\ e-mail: svitlana.serga@gmail.com
}

Aim. The aim of this study was to determine the Wolbachia infection prevalence among Drosophila species that are common in Ukraine. Methods. The total of 203 imago, representatives of seven Drosophila species collected from seven localities in Ukraine were screened for Wolbachia via PCR assay. Results. We found Wolbachia infection only in one individual of Drosophila testacea that was collected in the Chornobyl Exclusion Zone. Conclusions. In Ukraine, the examined Drosophila species are characterised by a low prevalence of Wolbachia infection. This research, together with previously reported infections in D. melanogaster and D. simulans populations, indicate that Wolbachia infects 3 out of 9 Drosophila species surveyed in Ukraine.

Keywords: Wolbachia, Drosophila, natural populations, D. testacea, endosymbiont.

Wolbachia is an obligate intracellular endosymbiont of arthropods that is widespread in nature [1]. Given the ability of Wolbachia to manipulate host 
reproduction [1], recent studies highlight the importance to research relationships between endosymbionts and their arthropod hosts in nature [2,3]. Nonetheless, most of such studies to date were either conducted on model organisms [4], or were related to pest control strategies [5], and thus even when examining multiple host species often lack biogeographical and ecological context [3, 6, 7]. Wolbachia are thought to infect from 20 to $50 \%$ of all the insect species, however these estimates are far from consensus, as actual prevalence of infection in nature remains to be unknown $[8,9]$. Moreover, with just few exceptions [10], there is a lack of studies systematically examining Wolbachia infection status in multiple host species that co-occur and interact within a given habitat.

The presence of Wolbachia has been confirmed in multiple Drosophila host species around the world, for example, in Drosophila melanogaster, D. simulans, D. suzukii and D. ananassea, whereas it has not been detected in a wide range of other species, including D. immigrans, D. repleta, D. obscura, etc. $[6,7,10,11]$. In Ukraine, Wolbachia are widely distributed in the natural populations of D. melanogaster [12] and D. simulans [13]. However, for other Drosophila species that are common in Ukraine [14], Wolbachia infection status remains to be unknown. Therefore, here we investigate the presence of Wolbachia infection in different Drosophila species that are common in Ukraine.

Materials and Methods. Flies were sampled from seven localities in Ukraine (Yalta, Odesa, Uman, Kharkiv, Pyriatyn, Varva, Chornobyl) during August ï October of 2015. A brief description of the sampled localities and their GPS coordinates can be found in Serga et al. [13]. Captured flies were assigned to the respective taxonomical group based on the external morphological features [15].

DNA extraction was performed from whole-bodies of adult flies of each species (D. repleta, D. hydei, D. obscura, D. subobscura, D. testacea, D. busckii and D. immigrans) using the high-salt method [16]. Wolbachia infection was tested by PCR using a set of primers to bacterial 16S rRNA gene (5ô  $w s p$ gene (81F 5ôTGGTCCAATAAGTGATGAAGAAAC, 691R 5ô 
AAAAATTAAACGCTACTCCA) [18]. To confirm obtained results, each PCR was repeated twice.

Results. We have analyzed 203 imagos, which belong to seven Drosophila species from seven localities in Ukraine to identify the presence of Wolbachia infection (Table 1). Examples of gel pictures displaying the PCR products of the $16 \mathrm{~S}$ $r R N A$ and $w s p$ gene fragments are presented in Figure 1. From all of the analyzed samples, only one DNA sample of Drosophila testacea collected from the Chornobyl Exclusion Zone was positive for Wolbachia.

Table 1

Wolbachia infection among different Drosophila species collected from natural populations in Ukraine

\begin{tabular}{|c|c|c|c|c|c|c|c|c|c|c|c|c|c|c|}
\hline \multirow{2}{*}{ Population } & \multicolumn{2}{|c|}{ Yalta } & \multicolumn{2}{|c|}{ Odesa } & \multicolumn{2}{|c|}{ Uman } & \multicolumn{2}{|c|}{ Kharkiv } & \multicolumn{2}{|c|}{ Varva } & \multicolumn{2}{|c|}{ Pyriatyn } & \multicolumn{2}{|c|}{ Chornobyl } \\
\hline & $N$ & $n$ & $N$ & $n$ & $N$ & $n$ & $N$ & $n$ & $N$ & $n$ & $N$ & $n$ & $N$ & $n$ \\
\hline D. repleta & 32 & 10 & 0 & 0 & 0 & 0 & 0 & 0 & 42 & 10 & 5 & 5 & 136 & 30 \\
\hline D. hydei & 0 & 0 & 10 & 10 & 41 & 10 & 0 & 0 & 1 & 1 & 0 & 0 & 99 & 50 \\
\hline D. obscura & 0 & 0 & 0 & 0 & 1 & 1 & 2 & 2 & 0 & 0 & 0 & 0 & 21 & 10 \\
\hline D. subobscura & 0 & 0 & 0 & 0 & 0 & 0 & 0 & 0 & 0 & 0 & 0 & 0 & 2 & 2 \\
\hline D. testacea & 0 & 0 & 0 & 0 & 0 & 0 & 0 & 0 & 0 & 0 & 0 & 0 & 1 & $1 *$ \\
\hline D. busckii & 0 & 0 & 0 & 0 & 0 & 0 & 0 & 0 & 0 & 0 & 0 & 0 & 1 & 1 \\
\hline D. immigrans & 7 & 7 & 37 & 20 & 1 & 1 & 8 & 8 & & & 5 & 5 & 19 & 19 \\
\hline
\end{tabular}

$N \ddot{\mathrm{i}}$ the total number of collected individuals; $n \ddot{\mathrm{i}}$ number of individuals that had been tested; * Wolbachia positive sample 


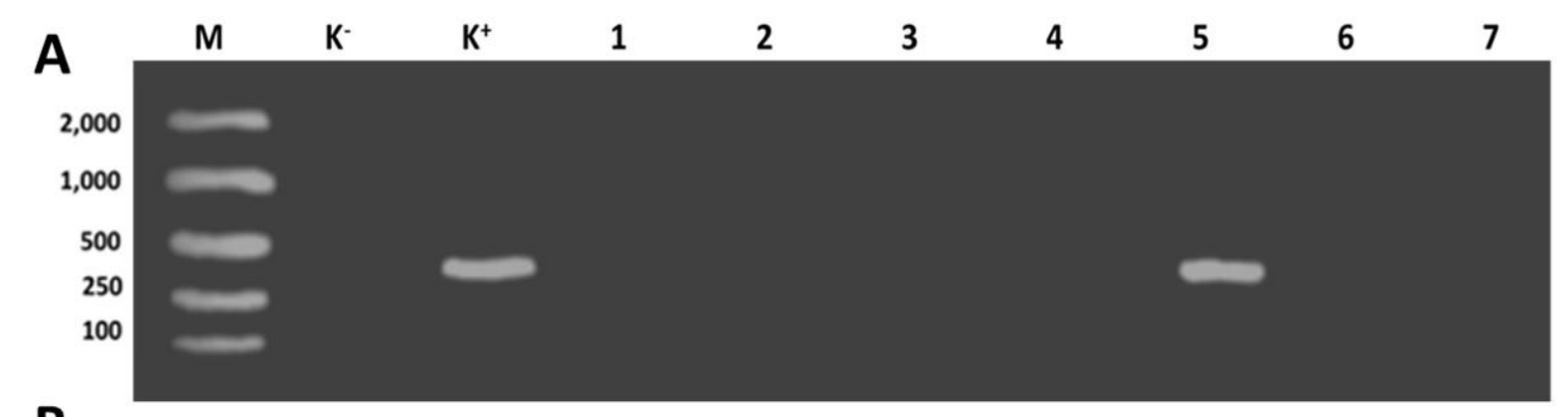

B

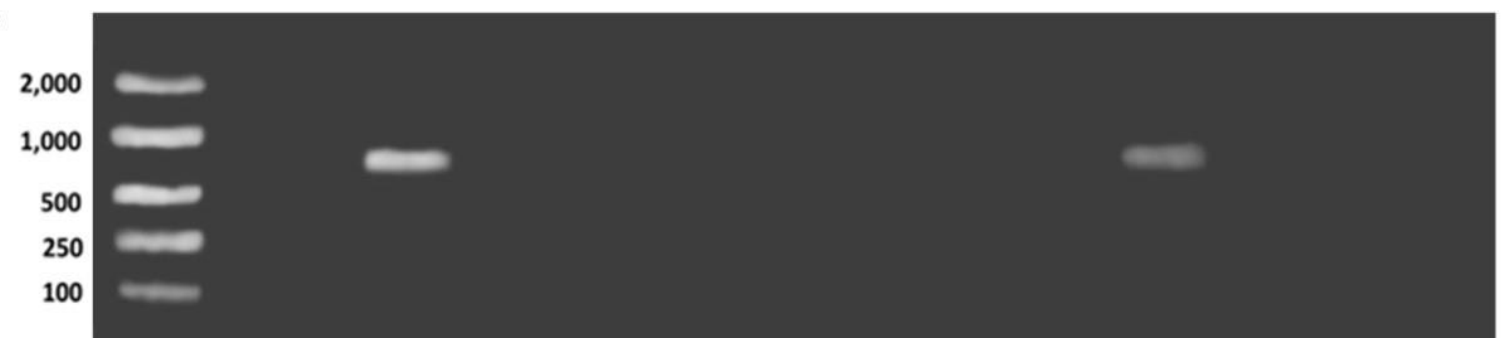

Fig. 1. Gel picture displaying PCR products of the $438 \mathrm{bp} 16 \mathrm{~S}$ rRNA (A) and 632 bp wsp (B) gene fragments, used for detection of Wolbachia infection Lanes: M Ï 100 bp DNA Ladder ñNew England BioLabsò; K- $\mathrm{K}^{-}$negative control; $\mathrm{K}^{+} \ddot{\mathrm{i}}$ positive control D. melanogaster; 1 ï D. testacea; 2 ï D. repleta; 3 ï D. hydei; 4 ï D. obscura; 5 ï D. subobscura; 6 ï D. busckii; 7 ï D. immigrans.

Discussion. Microorganisms have diverse implications for health, survival, fitness and adaptation of their animal hosts [1, 11]. Wolbachia are considered one of the most highly widespread bacteria among insects [8]. However, while Wolbachia are common among insects, its infection frequency and thus actual bacteria prevalence in nature are not ubiquitous and thus can be relatively low [3]. Indeed, the Drosophila species we surveyed in the present study, characterised by a low prevalence of Wolbachia infection, as from more than 200 samples spanning across seven Drosophila species, just one individual of $D$. testacea was confirmed to be positive for Wolbachia infection. Interestingly, Wolbachia has been previously reported in this species only once in a natural population located in France [19], despite the attempts to detect it in England [10] and Germany [20]. Wolbachia infects other species within D. testacea species group, such as Drosophila neotestacea [21] and Drosophila orientacea [20], although these species were not previously found from Ukraine. 
The low prevalence of Wolbachia infection in other tested Drosophila species from Ukraine may be due to specific ecological conditions at the sampling localities, which hinder Wolbachia distribution in the surveyed populations, although at the same localities Wolbachia infection frequencies are consistently high for D. melanogaster (43ï 78\%) [12] and D. simulans (100\%) [13]. Alternatively, negative status of Wolbachia infection in these species indicate that Wolbachia are not generally typical for these species in Ukraine and elsewhere. Indeed, other studies have also found no evidence for Wolbachia infection in six out of seven species examined here $[6,7,10,20]$.

Recent studies suggest that distribution and the overall prevalence of Wolbachia in nature might be overestimated [3]. Our results further corroborate these findings, at least for the Drosophila species surveyed in Ukraine. Thus, we suggest that future research should include wide range of host species to test whether it is a more general pattern similar across other insects.

Conclusions. While in Ukraine Wolbachia infection is widespread among the natural populations of D. melanogaster [12] and D. simulans [13], it was only detected in D. testacea and in no other Drosophil@ species examined in the present study. Therefore, Wolbachia infects only 3 out of 9 Drosophila species surveyed in Ukraine.

Acknowledgments. Authors thanks the staff of the Department of Biology at Mechnikov National University of Odesa, and the staff of the National Institute of Viticulture and Winemaking, National Academy of Agrarian Sciences of Ukraine, and Alexandra Protsenko and Mykhailo Lavrinienko for their invaluable help in material collection.

\section{乙C l

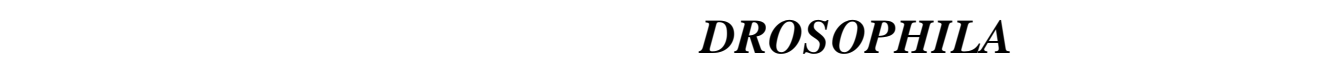

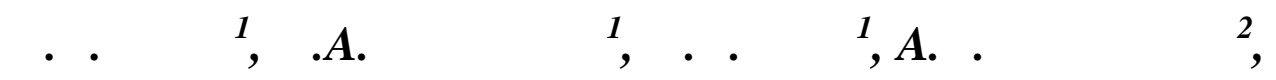

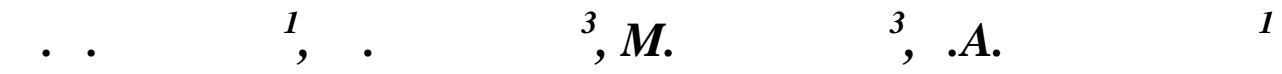




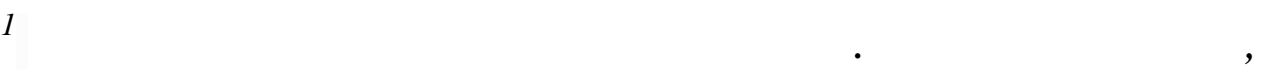

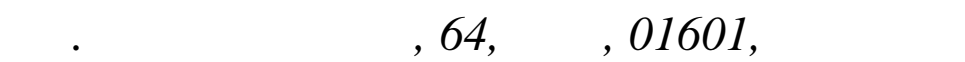

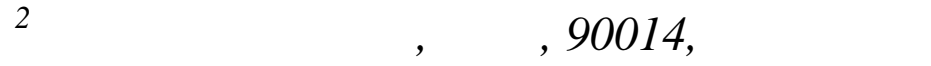

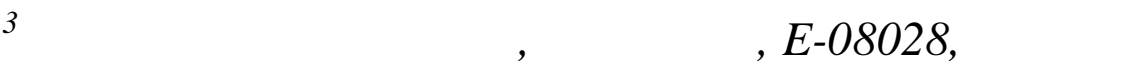

$t j L^{k} d \dot{s}$

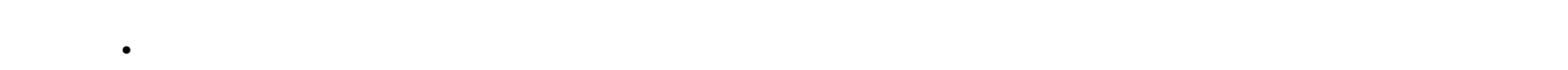

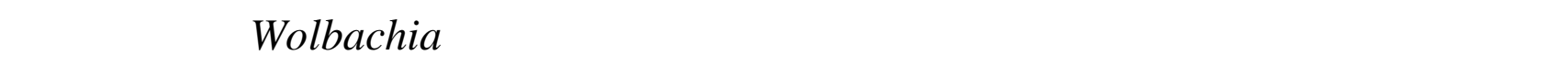

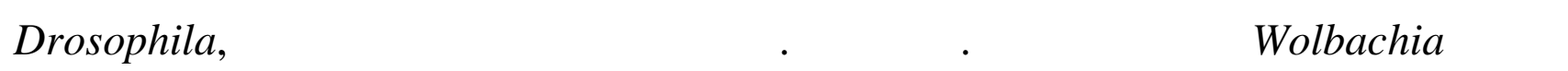

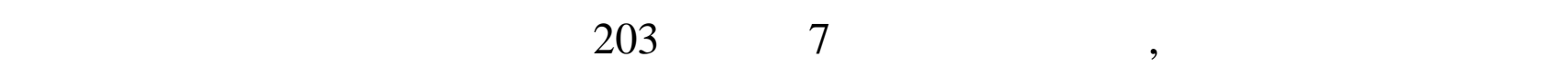

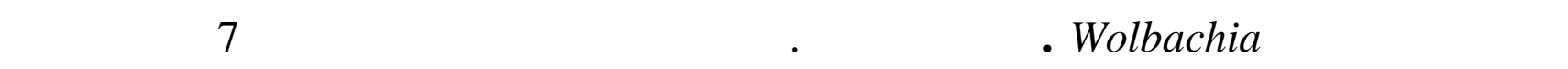

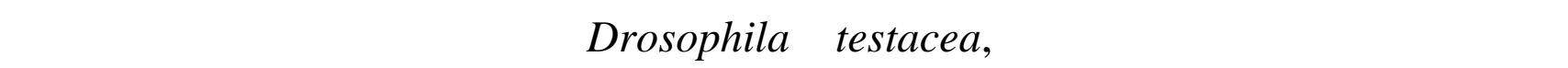

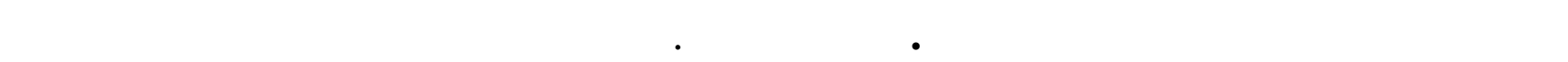

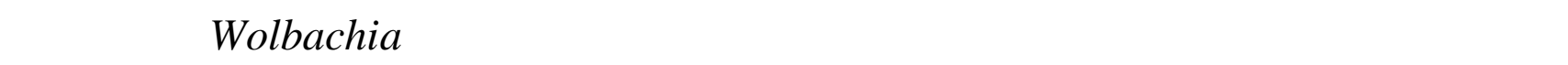

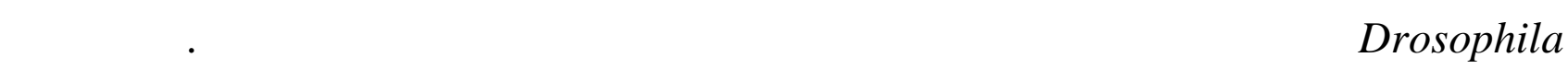

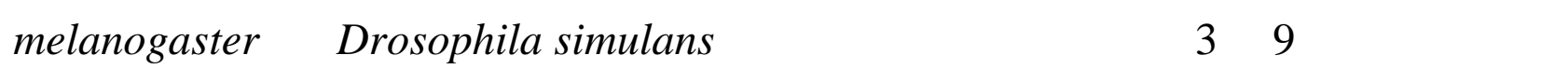

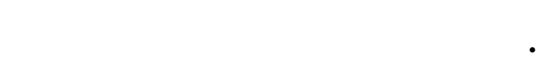

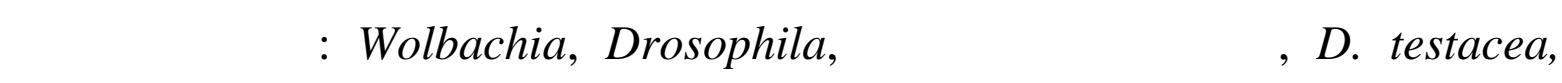

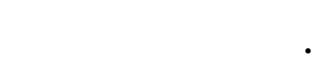

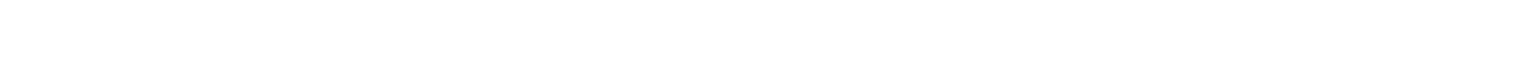

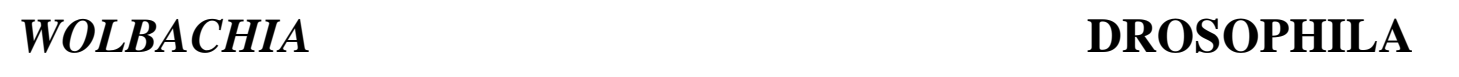 ust $\phi R$ l $\mathrm{C}$}

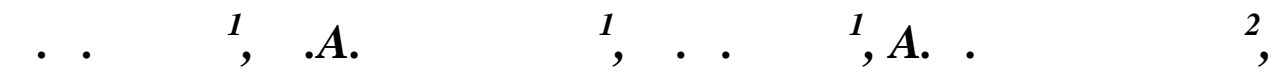

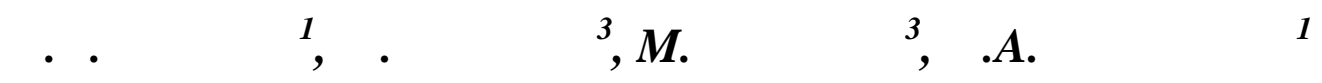

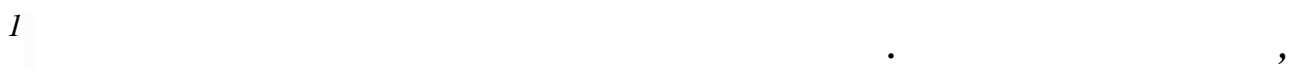

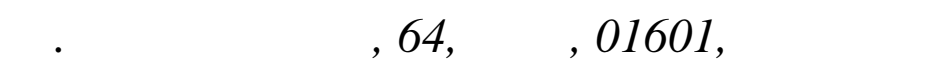

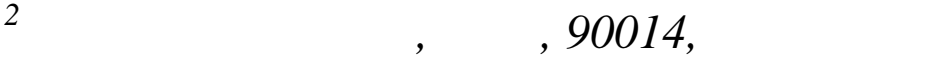

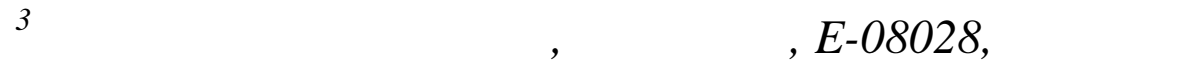

\section{$t j L^{b} d \dot{s}$}




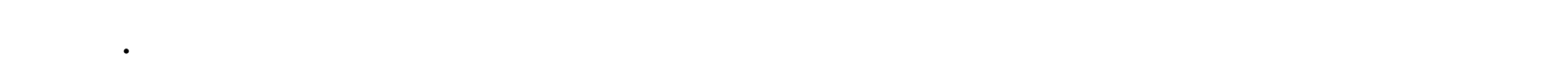

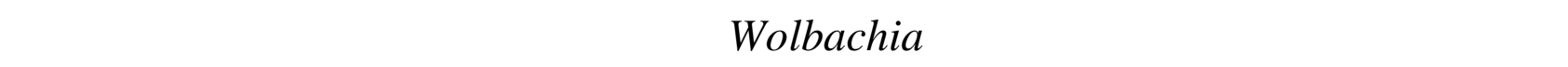

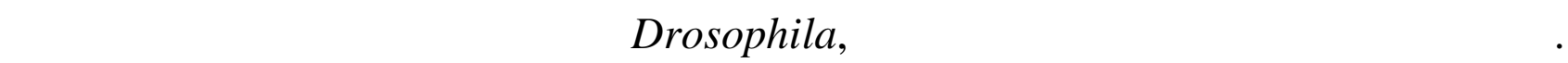

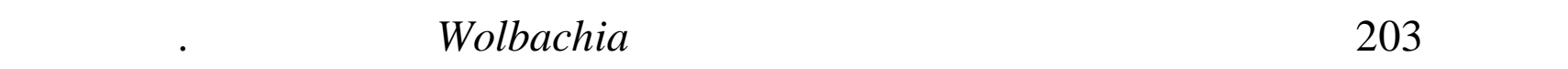
7 ơf

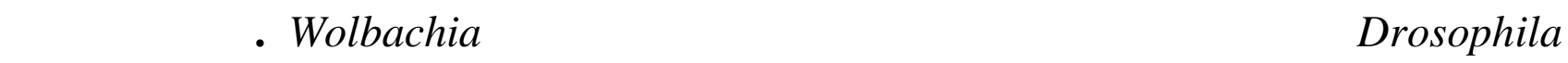

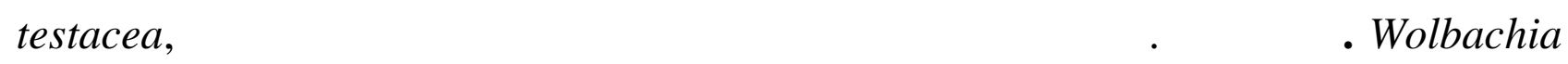

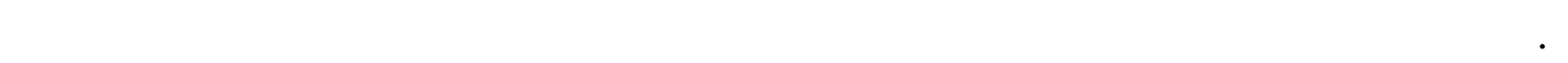

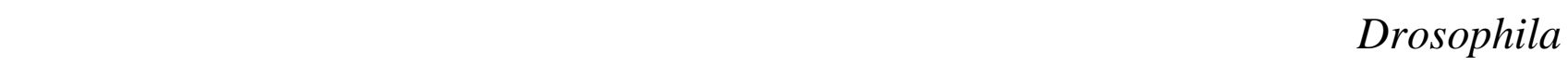

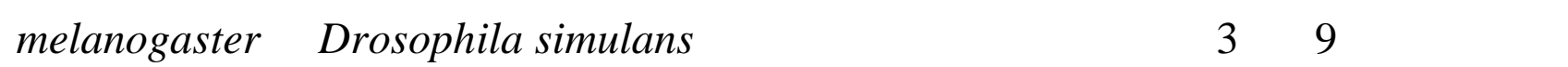

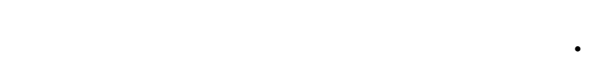

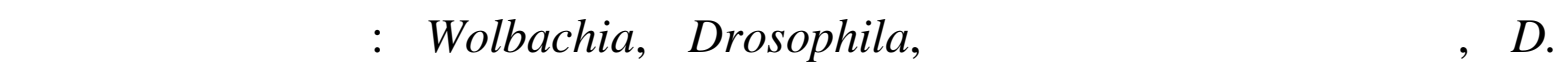

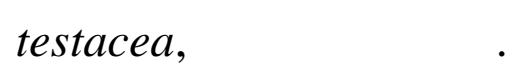

1. Belousov AO, Kozeretskaia IA. Symbiotic bacteria, which modify reproduction processes of Drosophila melanogaster. Mikrobiol zh. 2011; 73(2):43ї 52.

2. Mcneill MR, Richards NK, White JA, Laugraud A. Hidden arsenal: ¿ndosymbionts in arthropods, their role and possible implications for biological control success. N. Z. Plant Prot. 2014; 67:204ї 212.

3. Sazama EJ, Ouellette SP, Wesner JS. Bacterial endosymbionts are common among, but not necessarily within, insect species. Environmental Entomology. 2019; 48 (1):127ї 133. https://doi.org/10.1093/ee/nvy188

4. Kriesner P, Conner WR, Weeks AR, Turelli M, Hoffmann AA. Persistence of a Wolbachia infection frequency cline in Drosophila melanogaster and the possible role of reproductive dormancy. Evolution (N Y). 2016; 70:979ї 997.

5. Hamm CA, Begun DJ, Vo A, Smith CCR, Saelao P, Shaver AO, et al. Wolbachia do not live by reproductive manipulation alone: infection 
polymorphism in Drosophila suzukii and D. subpulchrella. Mol Ecol. 2014; 23:4871ї 4885.

6. Bourtzis K, Nirgianaki A, Markakis G. and Savakis C. Wolbachia infection and cytoplasmic incompatibility in Drosophila species. Genetics. 1996; 144:1063ї 1073.

7. Mateos M, Castrezana SJ, Nankivell BJ, Estes AM, Markow TA, Moran NA. Heritable Endosymbionts of Drosophila. Genetics. 2006; 174(1):363ї 376. doi:10.1534/genetics.106.058818.

8. Lo N, Paraskevopoulos C, Bourtzis K, O'Neill SL, Werren JH, Bordenstein SR, Bandi C. (2007) Taxonomic status of the intracellular bacterium Wolbachia pipientis. Int J Syst Evol Microbiol. 2007; 57:654ї 657.

9. Weinert LW, Araujo-Jnr EV, Ahmed MZ, Welch JJ. The incidence of bacterial endosymbionts in terrestrial arthropods. Proc Biol Sci. 2015; 282(1807):20150249.

10.Haine ER, Pickup N J and Cook JM. Horizontal transmission of Wolbachia in a Drosophila community. Ecol. Entomol. 2005; 30:464ї 472. doi: 10.1111/j.0307-6946.2005.00715.x

11. Serga SV, Kozeretskaya IA. The puzzle of Wolbachia spreading out through natural populations of Drosophila melanogaster. Zhurnal obshchey biologii. 2013; 74 (2):99ї 111. Russian.

12. Serga S, Maistrenko O, Rozhok A, Mousseau T, Kozeretska I. Fecundity as one of possible factors contributing to the dominance of the $w$ Mel genotype of Wolbachia in natural populations of Drosophila melanogaster. Symbiosis. 2014; 63(1):11ї 17. doi:10.1007/s13199-014-0283-1.

13. Serga S, Maistrenko O, Rozhok A, Mousseau T, Kozeretska I. Colonization of a temperate-zone region by the fruit fly Drosophila simulans (Diptera: Drosophilidae). Canadian Journal of Zoology. 2015; 93(10):799ї 804. doi: 10.1139/cjz-2015-0018. 
14. Lavrinienko A, Kesäniemi J, Watts $P C$ et al. First record of the invasive pest Drosophila suzukii in Ukraine indicates multiple sources of invasion. J Pest Sci. 2017; 90:421ï 429. doi: 10.1007/s10340-016-0810-3.

15. Bächli G, Vilela CR, Escher SA and Saura A. The Drosophilidae (Diptera) of Fennoscandia and Denmark. Netherlands, Leiden: Brill Publishing House. 2005. p. 1 362 (Fauna Entomologica Scandinavinca: Vol. 39).

16. Aljanabi S. Universal and rapid salt-extraction of high quality genomic DNA for PCR- based techniques. Nucleic Acids Res. 1997; 25(22):4692ï 4693. doi:10.1093/nar/25.22.4692

17. OôNeill S, [et al,]. 16S rRNA phylogenetic analysis of the bacterial endosymbionts associated with cytoplasmic incompatibility in insects. Proc Natl Acad Sci USA. 1992; 89(7):2699ї 2702.

18.Zhou W, Rousset F, OôNeill SL. Phylogeny and PCR-based classification of Wolbachia strains using wsp gene sequences. Proc R Soc Lond B Biol Sci. 1998; 265:509ї 515. doi: 10.1098/rspb.1998.0324.

19. Stahlhut J, Desjardins C, Clark M, Baldo L, Russell J, Werren J, and Jaenike J. The mushroom habitat as an ecological arena for global exchange of Wolbachia. Mol. Ecol. 2010; 19:1940ї 1952. doi: 10.1111/j.1365294X.2010.04572.x.

20. Werren J, Jaenike J. Wolbachia and cytoplasmic incompatibility in mycophagous Drosophila and their relatives. Heredity. 1995; 75:320ї 326.

21. Jaenike J, Stahlhut JK, Boelio LM, Unckless RL. Association between Wolbachia and Spiroplasma within Drosophila neotestacea: an emerging symbiotic mutualism? Mol Ecol. 2010; 19(2):414ї 25. doi:10.1111/j.1365294X.2009.04448.x.

ઈ Ltcodderts 19.12.2018 t6 